\title{
BMJ Open Cohort profile: the Brain and Mind Centre Optymise cohort: tracking multidimensional outcomes in young people presenting for mental healthcare
}

\author{
Joanne S Carpenter (D) , ${ }^{1}$ Frank lorfino (D) , ${ }^{1}$ Shane Cross (D) , ${ }^{1,2}$ Alissa Nichles, ${ }^{1}$ \\ Natalia Zmicerevska (D) ,' Jacob J Crouse (D) , ${ }^{1}$ Jake R Palmer (D) , , \\ Alexis E Whitton, ${ }^{1}$ Django White, ${ }^{1}$ Sharon L Naismith, ${ }^{1,2,4}$ Adam J Guastella, ${ }^{1}$ \\ Daniel F Hermens (D) , Jan Scott (1D) , ${ }^{1,6,7}$ Elizabeth M Scott (D) , 1,8 \\ Ian B Hickie (D) ${ }^{1}$
}

To cite: Carpenter JS, Iorfino F, Cross S, et al. Cohort profile: the Brain and Mind Centre Optymise cohort: tracking multidimensional outcomes in young people presenting for mental healthcare. BMJ Open 2020;10:e030985. doi:10.1136/ bmjopen-2019-030985

- Prepublication history and additional material for this paper are available online. To view these files, please visit the journal online (http://dx.doi org/10.1136/bmjopen-2019030985).

Received 10 April 2019 Revised 16 January 2020 Accepted 09 March 2020
D) Check for updates

(c) Author(s) (or their employer(s)) 2020. Re-use permitted under CC BY-NC. No commercial re-use. See rights and permissions. Published by BMJ.

For numbered affiliations see end of article.

\section{Correspondence to} Dr Joanne S Carpenter; joanne.carpenter@sydney. edu.au

\section{ABSTRACT}

Purpose The Brain and Mind Centre (BMC) Optymise cohort assesses multiple clinical and functional domains longitudinally in young people presenting for mental health care and treatment. Longitudinal tracking of this cohort will allow investigation of the relationships between multiple outcome domains across the course of care. Subsets of Optymise have completed detailed neuropsychological and neurobiological assessments, permitting investigation of associations between these measures and longitudinal course.

Participants Young people (aged 12-30) presenting to clinics coordinated by the BMC were recruited to a research register $(n=6743)$ progressively between June 2008 and July 2018. To date, 2767 individuals have been included in Optymise based on the availability of at least one detailed clinical assessment.

Measures Trained researchers use a clinical research proforma to extract key data from clinical files to detail social and occupational functioning, clinical presentation, self-harm and suicidal thoughts and behaviours, alcohol and other substance use, physical health comorbidities, personal and family history of mental illness, and treatment utilisation at the following time points: baseline, $3,6,12,24,36,48$, and 60 months, and time last seen. Findings to date There is moderate to substantial agreement between raters for data collected via the proforma. While wide variations in individual illness course are clear, social and occupational outcomes suggest that the majority of cohort members show no improvement in functioning over time. Differential rates of longitudinal transition are reported between early and late stages of illness, with a number of baseline factors associated with these transitions. Furthermore, there are longitudinal associations between prior suicide attempts and inferior clinical and functional outcomes.

Future plans Future reports will detail the longitudinal course of each outcome domain and examine multidirectional relationships between these domains both cross-sectionally and longitudinally, and explore in subsets the associations between detailed neurobiological measures and clinical, social and functional outcomes.
Strengths and limitations of this study

- This cohort tracks longitudinally a large number of young people presenting for mental health care and treatment early in the course of common mental disorders. It will provide detailed information about variations in the course of emerging illness over a prolonged, and developmentally sensitive, follow-up period.

- Multiple clinical and functional outcome domains will provide a rich dataset including assessment of social, educational and economic participation, physical health, alcohol and substance use, and deliberate self-harm and suicidal thoughts and behaviours.

- Linkage of longitudinal clinical data with more indepth assessments from related neuropsychological and neurobiological substudies will increase the potential for greater understanding of the pathophysiological correlates of illness course in young people.

- As data are obtained through extraction of information from clinical files, there is likely to be some under-reporting of items or missing data (both random and non-random). Availability of follow-up data is biassed towards those who remain in contact with mental health services.

\section{INTRODUCTION}

The significant excess of premature death and disability attributable to mental disorders is a function of early age of onset, prevalence, chronicity, comorbidity with physical illness and alcohol and substance misuse, and degree of resultant impairment. ${ }^{1-3}$ Notably, in those aged 10-24 years, neuropsychiatric disorders contribute more than any other cause to the global burden of disease. ${ }^{24}$ To reduce this burden, earlier identification and enhanced long-term care of those in the early phases of these disorders are key 
priorities. ${ }^{3}{ }^{5-9}$ Although $75 \%$ of mental disorders begin before the age of 25 years, ${ }^{10}$ current diagnostic thresholds and categories often map poorly onto the earlier phases of mental illness experienced by adolescents and young adults. ${ }^{112}$ Further, genetic, environmental, and neurobiological risk factor studies call into question the validity of specific diagnostic entities. ${ }^{13-18}$ Consequently, services have been developed in Australia to promote and support early intervention for young people with a broad range of mental and substance use disorders. This includes the expansion of headspace centres, from a network of 10-110 centres nationally from 2007 to $2018 .^{19}$ These services aim to reduce adverse long-term clinical, functional, and other health outcomes. ${ }^{72021}$

This paper reports on the methods, baseline characteristics, preliminary follow-up rates, and initial findings of the Brain and Mind Centre (BMC) Optymise (optimising early interventions for young people with emerging mood disorders) cohort. Optymise is an observational study tracking demographic, clinical, functional, and comorbid outcomes longitudinally in young people who present to enhanced primary care-based mental health services. These BMC clinics are not diagnostically specific, do not impose a symptoms, severity, or risk-related threshold for receiving care, and incorporate concurrent clinical, neurobiological and interventional research. Research within these services has the specific intent of studying the clinical, functional, and neurobiological correlates of the early phases of emerging mental disorders. ${ }^{7} 2021$ Typically, young people attending these services present with a broad range of anxiety, depressive, manic-like, psychotic-like, or comorbid syndromes.

For in-depth examination of this transdiagnostic cohort, we have proposed that it is essential to use a multidimensional clinical and functional assessment and outcomes framework. ${ }^{22-24}$ This framework overtly recognises that mental disorders are part of a broader general health construct, and are embedded within a social and neurodevelopmental context. Consequently, we propose five key clinical and functional dimensions: (1) social and occupational functioning (including social, educational and economic participation); (2) clinical presentation (including illness type, stage and trajectory); (3) self-harm and suicidal thoughts and behaviours (also incorporating concepts of accident and injury); (4) alcohol and other substance use; and (5) physical health comorbidities. Figure 1 shows the key domains of the multidimensional outcomes framework across time points and presents examples of potential cross-sectional and longitudinal relationships with particular emphasis on demonstrating the relationships between domains and not simply within the same domain over time. Social and occupational functioning is the primary outcome within this framework, due to the significance and persistence of impaired functioning in mentally ill populations (even during periods of syndromal remission) and its contribution to the burden of disease ${ }^{25-28}$ Clinical treatments and social and occupational interventions between time periods of assessment are recorded and are then considered in analyses as potential mediating or moderating variables.
T1

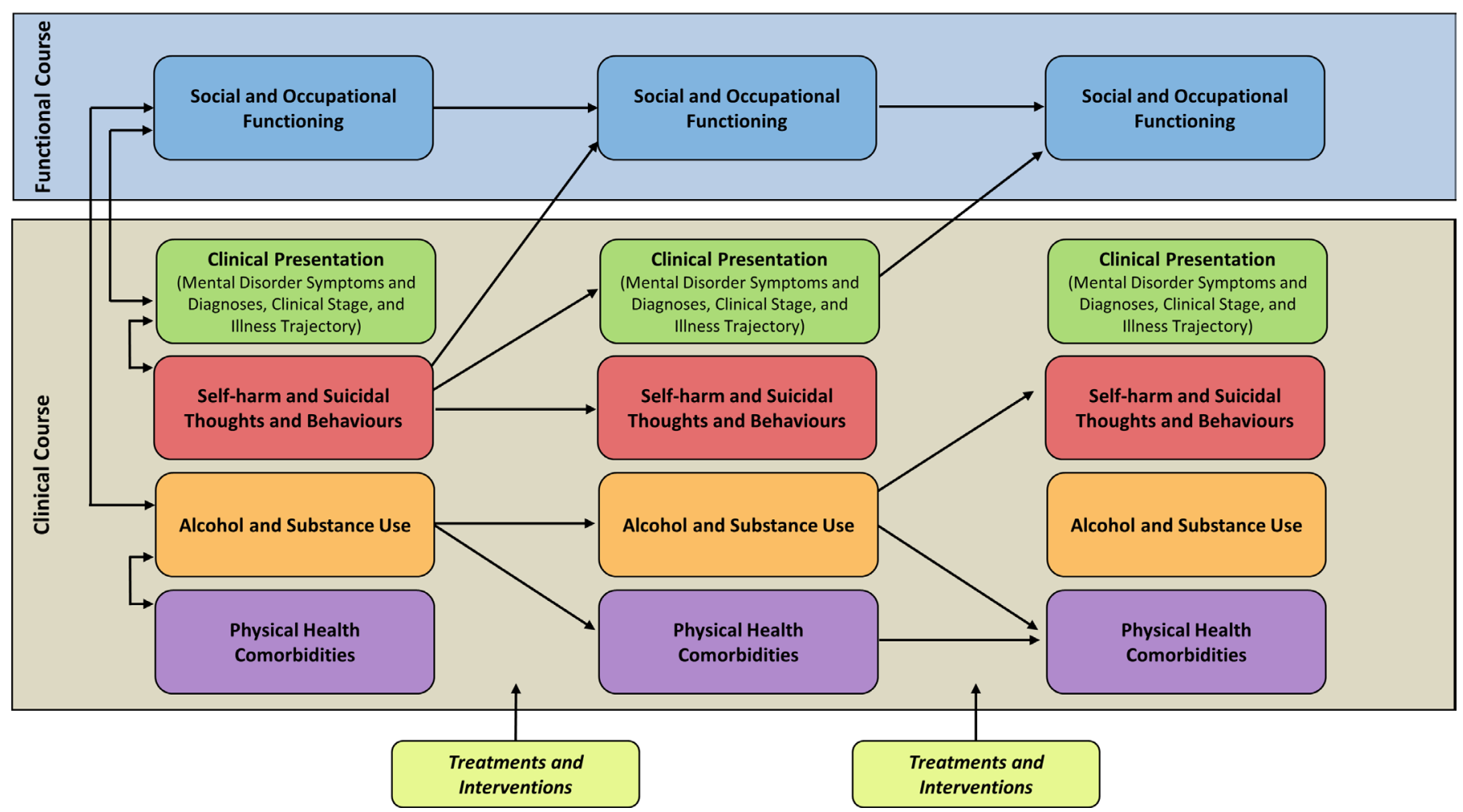

Figure 1 The multidimensional outcomes framework and examples of the potential relationships that operate across the various domains over time. 
The Optymise cohort has been established to provide longitudinal multidimensional outcomes data from a large, transdiagnostic sample of young people, who are typically presenting in the early stages of common mental illness syndromes. Recruitment is based on presentation for care and treatment rather than specific diagnostic criteria or severity thresholds, thus the findings are likely to translate well to other broadly based youth mental health and primary care settings. This focus on setting rather than diagnosis, severity, or risk-based recruitment is consistent with National Institute of Mental Health recommendations to conduct more inclusive clinical research in cohorts drawn from the same or similar settings. ${ }^{29-32}$ These inclusive cohorts are then more appropriate for the study of clinical or neurobiological constructs or dimensions of interest, and are also more likely to inform the development of more meaningful classification systems for common mental disorders.

Within the Optymise cohort, selected subgroups have been invited to take part in substudies with more in-depth measures of neuropsychological performance, structural and functional brain imaging, physical health (including anthropometric metabolic and immune function), and sleep-wake and circadian rhythms. These measures have been collected in large subsets of this population in various observational, longitudinal, and interventional studies conducted at the BMC. The Optymise cohort has been set up to maximise the use of data in these substudies by collecting broad information on individuals presenting to care, and linking individual clinical data between these associated studies and the cohort. This will enable more detailed investigation of the underlying neurobiology of mental illness in young people, as well as examination of the predictive value of such neurobiological measures in determining a range of long-term outcomes.

\section{COHORT DESCRIPTION \\ Participants}

Study participants are drawn from a larger cohort of $\mathrm{n}=6743$ individuals aged between 12 and 30 years who presented to the BMC's youth mental health clinics in the Sydney suburbs of Camperdown and Campbelltown and were recruited to a research register between June 2008 and July 2018. These clinics include primary care services branded as headspace, ${ }^{7021}$ as well as more specialised psychiatric services. The clinics primarily attract young people with a range of mental health problems (commonly anxious, mood, or psychotic syndromes) including those with subthreshold and full-threshold mental disorders. Young people may have been self-referred, referred via a family member or friend, or else via the community including external general practitioner, school, or university. ${ }^{7}$ All participants received clinician-based case management and relevant psychological, social, and/or medical interventions as part of standard care. This may have also included referral to more specialised mental health services, or hospitalisation, for those whose need exceeded the capacity of the primary care services.

All participants (and/or their guardians) gave written informed consent for the use of routinely collected clinical data for research purposes. No personally identifying information is recorded in the proforma in order to protect the privacy of the participants.

\section{Patient and public involvement}

Our headspace centres have an active patient advisory panel who are consulted regarding the development and application of research projects within our service. Findings from research studies are fed back to our young persons advisory group and to the users of our services. Results are also shared with regional and national health agencies, to assist with ongoing development of novel youth mental health services.

\section{Data collection}

Research staff were trained through individual and group training sessions to extract key data from clinical and research files and code inputs according to a specifically designed clinical research proforma (see 'Clinical proforma' below). Clinical files included all available notes and records from standard clinical care, and research files included various assessments as part of participation in substudies (which may include structured or unstructured clinical interviews and the use of symptom rating scales). The proforma records demographic, clinical, and functional information at predetermined time points. The first available clinical assessment at the service is taken as the baseline time point (T1) for each participant and the date of this assessment is used to determine each of the follow-up time points: T2 (3 months), T3 (6 months), T4 (12 months), T5 (2 years), T6 (3 years), T7 (4 years), and T8 ( 5 years). If there is no clinical information available for any time point (ie, the participant did not attend the service during that time), then that entry is left missing. A 'time last seen' (TLS) entry is also used to capture clinical information from the most recent presentation to the clinical service, which does not always align with one of the prespecified time points. All clinical and research notes from the preceding time points, up to and including the current time point are used to inform and complete the current proforma entry. The clinical research team responsible for collecting the data consult regularly to resolve ambiguities regarding any of the proforma items and ensure these are dealt with consistently.

As of December 2018, phase 1 of data entry has been completed, with 2767 participants included in the cohort and 78 excluded due to insufficient data. These participants were prioritised due to the richness of clinical and research data available, as a consequence of their participation in more detailed clinical or neurobiological substudies. Available data from the remaining 3898 will be entered progressively in phase 2 (commencing in 2019). New systematic data collection to determine 
long-term outcomes from all original participants, using novel digital technologies, is planned for 2020.

\section{Clinical proforma}

The clinical proforma captures key clinical information regarding the following:

\section{Demographics}

Biological sex is specified at baseline (T1), and age is calculated at each time point.

Current engagement in part-time or full-time education or employment is recorded to determine Not in Education, Employment, or Training (NEET) status. NEET is assigned if there was no full-time or part-time education, employment, training or volunteer work. Current receipt of any government benefits is also recorded.

\section{Social and occupational functioning}

The Social and Occupational Functioning Assessment Scale (SOFAS) ${ }^{33}$ is assessed at each time point. The SOFAS is a clinician-rated measure that assesses functioning on a $0-100$ scale, with lower scores suggesting more severe impairment. The instructions emphasise that the rater should aim to avoid confounding the rating with clinical symptoms (which has been noted as an issue with the Global Assessment of Functioning ${ }^{33-35}$ ). A SOFAS score of below 70 is considered to be clinically significant impairment. ${ }^{36}$

\section{Clinical presentation}

\section{Mental disorder diagnoses}

Mental disorder diagnoses at each time point are classified according to The Diagnostic and Statistical Manual of Mental Disorders (DSM-5) criteria ${ }^{37}$ and specified as either full-threshold or subthreshold. Diagnoses are also labelled as either primary, secondary, or tertiary based on judgement of which was the dominant presenting problem at that time point.

\section{Clinical stage}

Information about the course of illness is also used to assign a clinical stage at each time point according to a previously established model. ${ }^{6} 3839$ This model provides a framework to assess the clinical stage of mental illness based on current and previous severity and frequency of symptoms; characteristic mental features; age of onset and clinical course of illness prior to presentation; current level of risks of harm due to illness; previous treatment and hospital admissions; suicide attempts or other risk behaviours; and current levels of social, educational and economic participation. ${ }^{6}$ These stages are an adjunct to formal diagnosis and the demarcation between stages does not equate to the cut-offs for threshold diagnoses according to DSM-5 or other classification systems. Descriptions of the criteria for key stages (1a, 1b, and $2+)$ within this model are outlined in online supplementary appendix A and are detailed elsewhere. ${ }^{6}$ A decision tree outlining the clinical staging process is provided in figure 2. While stages 3 and 4 are also specified elsewhere for recurrent, persistent and chronic illness courses, stage 2 is our proposed cut-point for more persistent disorders requiring more specific and intensive clinical care and treatment. ${ }^{6839}$ Consistent with other models of clinical staging used elsewhere in medicine (eg, in oncology), while an individual may experience clinical remission across longitudinal assessment, they cannot go back across stages when assessed at follow-up points.

\section{Pathophysiological mechanisms}

Participants with any type of mood syndrome are also allocated to one of three proposed pathophysiological mechanisms on the basis of the description of the clinical presentation. Any cases with significant maniclike symptoms (manic, hypomanic, or brief hypomanic phenomena) or significant atypical features (eg, reduced activation and energy, prolonged sleep, prolonged fatigue) are allocated to the 'circadian-bipolar spectrum' subtype. Cases with a primary psychotic disorder or significant and persistent developmental difficulties (such as autism spectrum disorder (ASD), specific learning disability, or low IQ) are allocated to the 'neurodevelopmentalpsychosis' subtype. Remaining cases-typically those reporting childhood anxiety and later stress-sensitivity with evolving depressive disorder symptoms are allocated to the 'hyperarousal-anxious depression' subtype. Allocation to these pathophysiological mechanisms is intended as an adjunct to the clinical staging model and has been described in detail previously. ${ }^{40-42}$ The clinical presentation is reviewed at each time point to assess the emergence of mania-fatigue or developmental-psychosis syndromes. As the entire clinical history is used to inform allocation to these categories, individuals assigned a circadian-bipolar spectrum or neurodevelopmental-psychosis phenotype cannot be assigned to the anxiety-depression phenotype at a later time point.

\section{At-risk mental states}

Clusters of symptoms that have been previously indicated as risk factors for progression to more severe mental disorders ${ }^{43-48}$ are recorded in all individuals regardless of diagnosis. This includes psychotic-like experiences (the presence of any psychotic symptoms including perceptual abnormalities, bizarre ideas, disorganised speech, psychotic-like unusual language or thought content, or psychotic-like disruptive or aggressive behaviour), maniclike experiences (the presence of any manic/hypomanic symptoms including abnormally elevated mood or irritability; increased motor activity, speech, or sexual interest; manic-like disruptive or aggressive behaviour; manic-like unusual language or thought content; increased goal directed behaviour; or decreased need for sleep), and circadian disturbance (the presence of significant disruption in sleep-wake or circadian cycles including the presence of a severe sleep-wake disorder or chronic fatigue). The distinction between psychotic-like and manic-like symptoms is judged within the context of the clinical notes. 


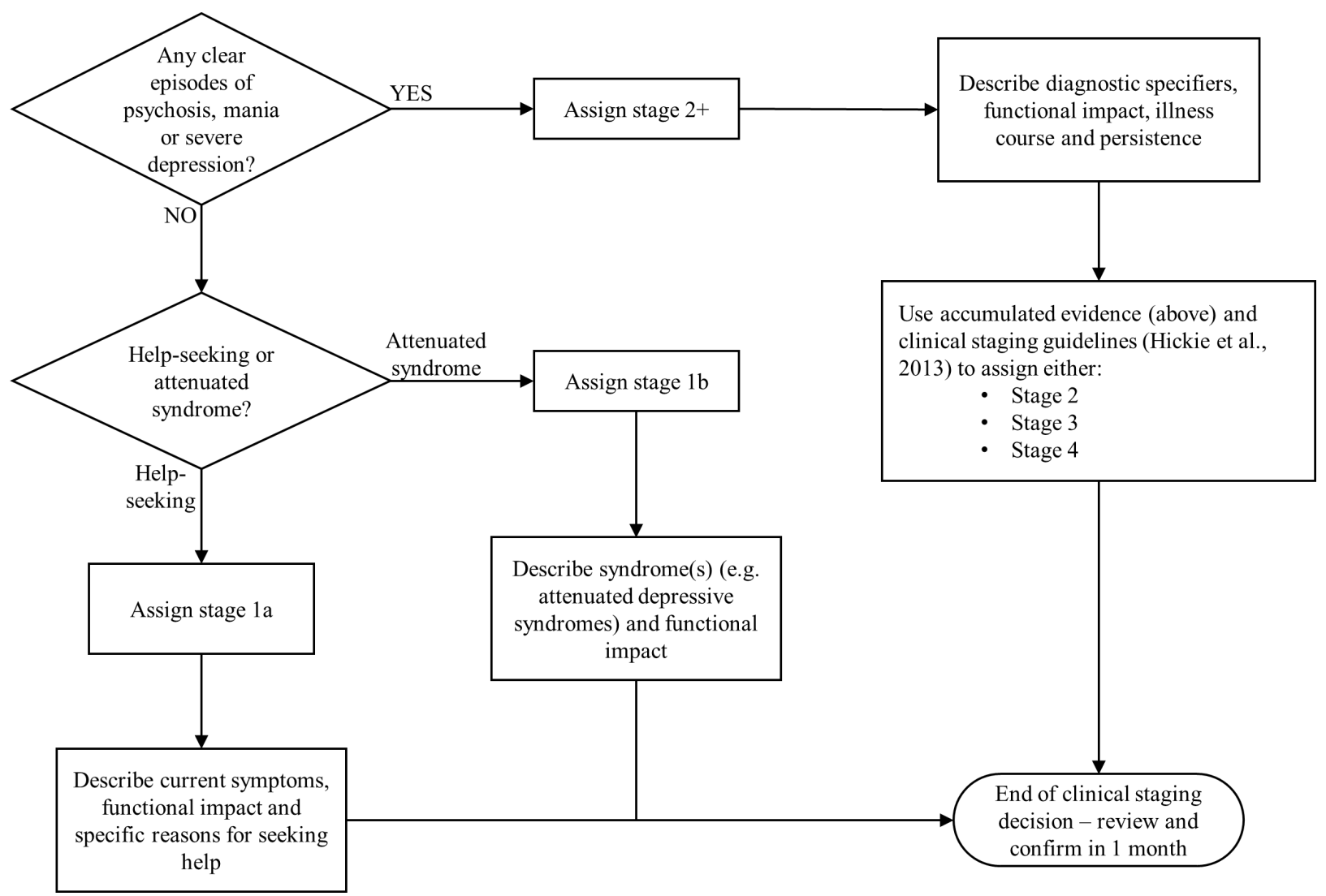

Figure 2 The stepwise process taken to assign those presenting for mental health care and treatment to the appropriate clinical stage.

\section{Self-harm and suicidal thoughts and behaviours}

The presence of suicidal ideation, suicide planning, suicide attempts, and deliberate self-harm since the previous available time point is recorded. A suicide attempt is recorded when a young person has actually taken steps to take their own life. If an individual harms themselves via cutting, hitting themselves, burning themselves, or scratching with the intention to self-harm only and not to take their life, then this is included as selfharm and not a suicide attempt. If a suicide attempt occurs it is also recorded whether the attempt resulted in hospitalisation or presentation to a hospital emergency department.

\section{Alcohol and substance use}

The presence of any reported use of tobacco, alcohol, cannabis, stimulants, or other drugs since the previous available time point is recorded.

\section{Physical health comorbidities}

Any major physical illness is recorded and assigned to a category based on type of illness.

\section{Personal mental illness history}

Known childhood-onset disorders (ie, with clear onset prior to 12 years old) are recorded in addition to current diagnoses.

\section{Family history of mental illness}

Known family history of mental illness in first-degree relatives is recorded.

\section{Treatment utilisation}

Exposure to classes of medication (antidepressant, antipsychotic, mood stabiliser, or stimulant medication) since the previous available time point, and hospitalisation overnight or longer due to a mental health problem since the previous available time point (including specification of hospitalisation due to illness severity or suicidality) are recorded.

\section{Inter-rater reliability}

An inter-rater reliability (IRR) analysis was performed using T1 proforma recordings for 66 participants that were completed independently by three raters. Fleiss' kappa was computed for nominal variables, and intraclass correlation coefficient (ICC) was computed for ordinal and continuous variables (see online supplementary appendix B). ${ }^{49}$

IRR estimates generally indicated moderate (kappa $>0.4$ ) to substantial (kappa $>0.6$ ) agreement, with excellent agreement (kappa>0.8) for some variables, typically those with clear defining features that would be expected to be well documented in clinical notes, such as psychotic illness, obsessive compulsive disorder, ASD and use of antidepressant or antipsychotic medication. 


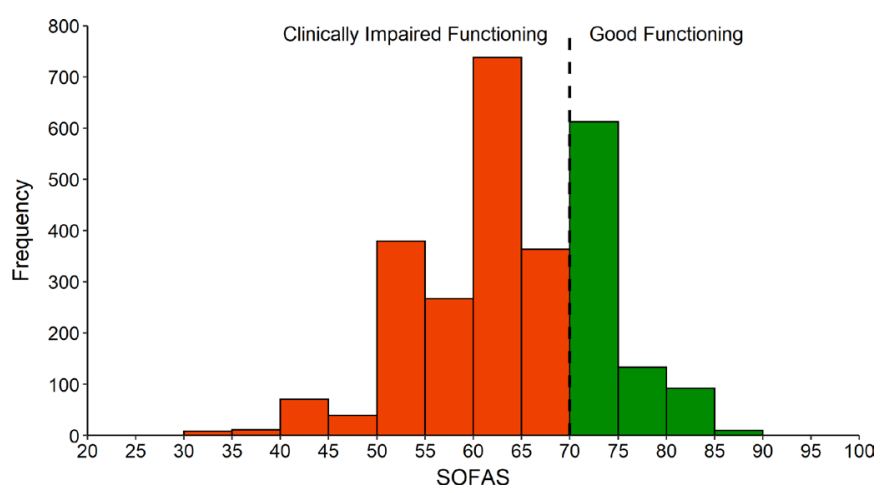

Figure 3 Distribution of Social and Occupational Functioning Assessment Scale (SOFAS) scores in the Optymise cohort at baseline.

Lower reliability estimates (in the fair range: kappa 0.2-0.4) were found for some variables, including receipt of government benefits, the presence of a trauma-related or personality disorder syndrome, suicide attempts, the presence of circadian disturbance, and the receipt of psychological therapy. Reliability estimates for childhood anxiety or other neurodevelopmental disorders (ie, other than ASD or attention deficit hyperactivity disorder) were in the poor range (kappa $\leq 0.2)$. This indicates some variation in the scoring of these items between raters. The prevalence of some variables was too low to warrant calculation of IRR indices; caution should be exercised in the interpretation of analyses involving these variables.

\section{Baseline characteristics}

Of the 6743 individuals in the research register (mean age at presentation to clinical services $\pm \mathrm{SD}: 18.4 \pm 3.8$ years, $57.3 \%$ female), 2767 participants have been included in phase 1 of data entry for the current study (mean age at study baseline \pm SD: $18.8 \pm 3.8$ years, $58.2 \%$ female) based on the availability of at least one time point of clinical data, 78 have been excluded due to insufficient data, and 3898 are yet to be entered in phase 2 of data entry for this cohort.

Occupational status indicated that $17.4 \% \quad(n=481)$ were NEET; $63.7 \% \quad(n=1763)$ were engaged in fulltime education, employment and/or training; $14.3 \%$ $(n=397)$ were engaged in part-time education, employment and/or training; and for $4.6 \%(n=126)$ it was unclear whether there was any current occupational engagement. Ratings on the SOFAS ranged from 30 to 90 , with a mean of $62.1 \pm 9.4$. The distribution of baseline SOFAS scores is shown in figure 3; 68.6\% $(n=1876)$ had a SOFAS score less than 70, indicating clinically significant impairment.

Presenting syndromes at baseline are reported in table 1, with more detailed full-threshold and subthreshold diagnoses reported in online supplementary appendix C. Clinical stage, proposed pathophysiological mechanisms, and at-risk mental states are reported in table 2; the prevalence of self-harm and suicidal thoughts and behaviour, alcohol and substance use, and physical health comorbidities are reported in table 3 ; and the prevalence of clinical course characteristics are reported in table 4 .

\section{Preliminary follow-up rates}

Of the 2767 included participants, 2336 had at least one follow-up time point (that was in the range of $\mathrm{T} 2$ or later, that is, at least 1 month after baseline). The median duration of follow-up from baseline to time last seen was 14.4

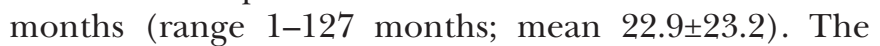
number of participants with available data and demographic characteristics for those with data at each time

Table 1 Presenting syndromes in the Optymise cohort at baseline

\begin{tabular}{|c|c|c|c|c|}
\hline & \multicolumn{2}{|c|}{ Primary presenting syndrome } & \multicolumn{2}{|c|}{ Any presenting syndrome } \\
\hline & $\mathbf{N}$ & Percentage of sample & $\mathbf{N}$ & Percentage of sample \\
\hline Depressive disorder & 1203 & $43.5 \%$ & 1821 & $65.8 \%$ \\
\hline Anxiety disorder & 576 & $20.8 \%$ & 1633 & $59.0 \%$ \\
\hline Bipolar or related disorder & 232 & $8.4 \%$ & 288 & $10.4 \%$ \\
\hline Schizophrenia spectrum or other psychotic disorder & 183 & $6.6 \%$ & 245 & $8.9 \%$ \\
\hline Neurodevelopmental disorder & 158 & $5.7 \%$ & 388 & $14.0 \%$ \\
\hline Disruptive, impulse-control or conduct disorder & 81 & $2.9 \%$ & 195 & $7.1 \%$ \\
\hline Trauma-related or stressor-related disorder & 109 & $3.9 \%$ & 223 & $8.1 \%$ \\
\hline Substance-related or addictive disorder & 58 & $2.1 \%$ & 272 & $9.8 \%$ \\
\hline Obsessive-compulsive or related disorder & 40 & $1.5 \%$ & 139 & $5.0 \%$ \\
\hline Eating disorder & 27 & $1.0 \%$ & 135 & $4.9 \%$ \\
\hline Personality disorder & 24 & $0.9 \%$ & 93 & $3.4 \%$ \\
\hline Other disorder & 57 & $2.1 \%$ & 114 & $4.1 \%$ \\
\hline No psychiatric syndrome & 19 & $0.7 \%$ & & \\
\hline
\end{tabular}

Any presenting syndrome includes any full-threshold or subthreshold primary, secondary, or tertiary diagnoses. 'Other disorder' includes gender dysphoria, dissociative disorders, sleep-wake disorders, and somatic disorders. 
Table 2 Clinical stage, developmental trajectories, and atrisk mental states in the Optymise cohort at baseline

\section{N Percentage} of sample

Clinical stage

\begin{tabular}{lll} 
Stage 1a & 804 & $29.1 \%$ \\
\hline Stage 1b & 1625 & $58.7 \%$ \\
\hline Stage 2+ & 338 & $12.2 \%$ \\
\hline
\end{tabular}

Proposed pathophysiological

mechanism

\begin{tabular}{|lll|}
\hline Hyperarousal-anxious depression & 2024 & $73.2 \%$ \\
\hline Neurodevelopmental-psychosis & 346 & $12.5 \%$ \\
\hline Circadian-bipolar spectrum & 303 & $11.0 \%$ \\
\hline No mood syndrome & 94 & $3.4 \%$ \\
\hline At-risk mental states & & \\
\hline Psychosis-like experiences & 599 & $21.7 \%$ \\
\hline Mania-like experiences & 460 & $16.6 \%$ \\
\hline Circadian disturbance & 410 & $14.8 \%$ \\
\hline
\end{tabular}

point are shown in table 5. Follow-up data will be reported in more detail in subsequent publications.

\section{FINDINGS TO DATE}

The BMC Optymise cohort includes individuals between 12 and 30 years old, and the mean age at baseline was approximately 19 years old, consistent with the target demographic of the early intervention youth services. The gender distribution of this cohort was similar to that reported generally in young Australians with mental disorders ${ }^{50}$ with around $58 \%$ female, but there was a slightly smaller proportion of females than estimated in the national population of individuals presenting to headspace centres. ${ }^{51}$ The sample with available data at each of the longitudinal follow-up time points were fairly similar to the baseline sample in terms of age; however, the percentage of female participants increased at longer follow-up intervals, suggesting that females in this population may engage with care for longer periods of time.

Baseline social and occupational functioning as measured by SOFAS ranged from good functioning to a complete inability to function, with the average in the range of moderate impairment and close to $70 \%$ of the sample in the range of clinically significant impairment, demonstrating the widespread nature of functional impairment early in the course of mental illness. ${ }^{52-54}$ Further, approximately $17 \%$ were already not engaged in education, employment or training at baseline, similar to the rate reported in headspace clients nationally ${ }^{55}$ and higher than general population estimates in this age group (11.4\% of Australians aged $15-29$ years old) ${ }^{56}$ Our initial report on changes in social and occupational functioning across the course of care in this cohort ${ }^{57}$ indicates that only around a quarter of participants experience
Table 3 Prevalence of self-harm and suicidal thoughts and behaviour, alcohol and substance use, and physical health comorbidities in the Optymise cohort at baseline

\begin{tabular}{|c|c|c|}
\hline & $\mathbf{N}$ & $\begin{array}{l}\text { Percentage } \\
\text { of sample }\end{array}$ \\
\hline \multicolumn{3}{|l|}{$\begin{array}{l}\text { Self-harm and suicidal thoughts and } \\
\text { behaviour }\end{array}$} \\
\hline Deliberate self-harm & 1013 & $36.6 \%$ \\
\hline Suicidal Ideation & 1240 & $44.8 \%$ \\
\hline Suicide planning & 489 & $17.7 \%$ \\
\hline Suicide attempt(s) & 379 & $13.7 \%$ \\
\hline Hospitalisation for suicide attempt & 219 & $7.9 \%$ \\
\hline \multicolumn{3}{|l|}{ Alcohol and substance use } \\
\hline Any alcohol or substance use & 1853 & $67.0 \%$ \\
\hline Alcohol use & 1724 & $62.3 \%$ \\
\hline Cannabis use & 1083 & $39.1 \%$ \\
\hline Tobacco use & 1048 & $37.8 \%$ \\
\hline Stimulant use & 570 & $20.6 \%$ \\
\hline Other drug use & 432 & $15.6 \%$ \\
\hline \multicolumn{3}{|l|}{ Physical health comorbidities } \\
\hline Any major physical illness & 447 & $16.2 \%$ \\
\hline Respiratory illness & 129 & $4.7 \%$ \\
\hline Neurological illness & 87 & $3.1 \%$ \\
\hline Endocrine illness & 77 & $2.8 \%$ \\
\hline Metabolic illness & 49 & $1.8 \%$ \\
\hline Infective illness & 28 & $1.0 \%$ \\
\hline Immune illness & 26 & $0.9 \%$ \\
\hline Gastrointestinal illness & 24 & $0.9 \%$ \\
\hline Musculoskeletal illness & 20 & $0.7 \%$ \\
\hline Gynaecological illness & 19 & $0.7 \%$ \\
\hline Pain-related illness & 19 & $0.7 \%$ \\
\hline Cardiovascular illness & 12 & $0.4 \%$ \\
\hline Skin-related illness & 13 & $0.5 \%$ \\
\hline Blood-related illness & 10 & $0.4 \%$ \\
\hline Allergic illness & 9 & $0.3 \%$ \\
\hline Cancer or tumour-related illness & 7 & $0.3 \%$ \\
\hline Renal or urinary illness & 4 & $0.1 \%$ \\
\hline Hearing-related illness & 3 & $0.1 \%$ \\
\hline Ophthalmic illness & 2 & $0.1 \%$ \\
\hline
\end{tabular}

reliable improvement, with functioning either deteriorating or remaining the same in the majority. This chronic functional impairment should be a high priority target for intervention efforts, given the significant contribution of poor functioning to the burden of disease, ${ }^{2527}$ and associations between poor functioning and other adverse outcomes. ${ }^{58-60}$

Baseline diagnostic information indicates that the most common primary presenting problem was a depressive syndrome, followed by anxiety, bipolar, and psychotic 
Table 4 Clinical course characteristics in the Optymise cohort at baseline

\begin{tabular}{|c|c|c|}
\hline & $\mathbf{N}$ & $\begin{array}{l}\text { Percentage } \\
\text { of sample }\end{array}$ \\
\hline \multicolumn{3}{|l|}{ Personal mental illness history } \\
\hline Any childhood disorder & 364 & $13.2 \%$ \\
\hline Childhood ADHD & 151 & $5.5 \%$ \\
\hline Childhood ASD & 77 & $2.8 \%$ \\
\hline Childhood anxiety disorder & 66 & $2.4 \%$ \\
\hline $\begin{array}{l}\text { Other childhood } \\
\text { neurodevelopmental disorder }\end{array}$ & 56 & $2.0 \%$ \\
\hline Childhood depression & 41 & $1.5 \%$ \\
\hline $\begin{array}{l}\text { Childhood behavioural or } \\
\text { conduct disorder }\end{array}$ & 24 & $0.9 \%$ \\
\hline Childhood OCD & 12 & $0.4 \%$ \\
\hline Other childhood disorder & 11 & $0.4 \%$ \\
\hline \multicolumn{3}{|l|}{$\begin{array}{l}\text { Family history in first-degree } \\
\text { relatives }\end{array}$} \\
\hline $\begin{array}{l}\text { Any family history of mental } \\
\text { illness }\end{array}$ & 1270 & $45.9 \%$ \\
\hline $\begin{array}{l}\text { Family history of depressive } \\
\text { disorder }\end{array}$ & 835 & $30.2 \%$ \\
\hline Family history of anxiety disorder & 404 & $14.6 \%$ \\
\hline $\begin{array}{l}\text { Family history of alcohol use } \\
\text { disorder }\end{array}$ & 249 & $9.0 \%$ \\
\hline Family history of bipolar disorder & 216 & $7.8 \%$ \\
\hline $\begin{array}{l}\text { Family history of substance use } \\
\text { disorder }\end{array}$ & 184 & $6.7 \%$ \\
\hline $\begin{array}{l}\text { Family history of psychotic } \\
\text { disorder }\end{array}$ & 126 & $4.6 \%$ \\
\hline Family history of suicide & 44 & $1.6 \%$ \\
\hline \multicolumn{3}{|l|}{ Treatment Utilisation } \\
\hline Psychological therapy & 1501 & $54.3 \%$ \\
\hline Any psychiatric medication & 1373 & $49.6 \%$ \\
\hline Antidepressants & 1068 & $38.6 \%$ \\
\hline Antipsychotics & 475 & $17.2 \%$ \\
\hline Stimulants & 244 & $8.8 \%$ \\
\hline Mood stabilisers & 209 & $7.6 \%$ \\
\hline Any hospitalisation & 635 & $23.0 \%$ \\
\hline Hospitalisation due to severity & 281 & $10.2 \%$ \\
\hline Hospitalisation due to suicidality & 218 & $7.9 \%$ \\
\hline
\end{tabular}

ADHD, attention deficit hyperactivity disorder; ASD, autism spectrum disorder; OCD, obsessive compulsive disorder.

syndromes. This is consistent with reports that, although anxiety disorders are the most prevalent mental illnesses in young people,$^{5061} \mathrm{mood}$ disorders are generally associated with greater help-seeking and service use. ${ }^{62} 63$ The prevalence rates of full-threshold diagnoses were slightly higher in our sample than those reported in headspace clients nationally. ${ }^{51}$ For almost all diagnostic categories, the prevalence of subthreshold or unspecified cases was greater than the prevalence of full-threshold disorders (see online supplementary appendix $\mathrm{C}$ ), highlighting that, despite being help-seeking, the majority of our sample experience syndromes that do not meet formal diagnostic criteria at presentation to care. This illustrates the inadequacy of traditional diagnostic classification systems for describing the experiences of young people at early stages of mental disorders, in whom levels of distress and disability are high, clearly warranting intervention even in the absence of such formal diagnoses. ${ }^{7164-66}$

Further, the prevalence of at-risk mental states was more substantial than both full-threshold and subthreshold bipolar and psychotic diagnoses, suggesting that such features are common in those presenting to youth mental health services, occurring much more frequently than overt psychotic or bipolar disorders. The prevalence of psychosis-like experiences in this sample is higher than the $6 \%-12 \%$ reported in adults and adolescents in the general population ${ }^{67-69}$ but lower than previous reports in young people presenting for mental healthcare, which have found prevalence closer to $50 \%$ even in nonpsychotic samples. ${ }^{71}$ The more conservative prevalence in the current study is likely due to the method of data collection, as less severe psychosis-like symptoms may not have been specifically assessed or recorded by clinicians.

The distribution across clinical stages of young people presenting to our early intervention services has varied somewhat across previous reports ${ }^{7} 6466$ 72; however, the broadly consistent pattern of the majority of cases presenting at earlier stages ( $1 \mathrm{a}$ or $1 \mathrm{~b})$ is reproduced in the present sample. The present study provides the largest sample to date with clinical stage data using this model, and assessment at the earliest available clinical time point provides an estimate of the distribution across stages as close to first presentation to care as possible. Our report on longitudinal transition rates from earlier to later clinical stages in the Optymise cohort indicates a low risk of progression to later stages in those presenting at stage $1 \mathrm{a}$, and a more substantial risk of progression in those presenting at stage $1 \mathrm{~b} .^{73} \mathrm{~A}$ number of baseline factors are associated with these transitions including manic-like and psychotic-like experiences and lower social and occupational functioning for stage $1 \mathrm{a}$ to $1 \mathrm{~b}$ transitions, and psychotic-like experiences and circadian disturbance for stage $1 \mathrm{~b}$ to $2+$ transitions. $^{73}$

The proportion of individuals assigned to the three proposed pathophysiological mechanisms (hyperarousalanxious depression, circadian-bipolar spectrum, and neurodevelopmental-psychosis) differed somewhat from previous reports, ${ }^{40} 74$ with a greater proportion of the current sample in the hyperarousal-anxious depression subtype. This is likely due to the fact that the current report describes the profile of individuals at the first available clinical time point, whereas previous reports have used all available information, and have not been 
Table 5 Key baseline characteristics of included participants at each time point

Baseline 3 months 6 months 12 months 24 months 36 months 48 months 60 months

\begin{tabular}{lllllllll}
\hline $\mathrm{N}$ & 2767 & 1690 & 1257 & 1074 & 691 & 466 & 288 & 199 \\
Sex (\% female) & 58.2 & 59.6 & 61.7 & 61.6 & 59.2 & 63.1 & 63.5 & 63.3 \\
Baseline age (mean \pm SD) & $18.8 \pm 3.8$ & $18.4 \pm 3.6$ & $18.4 \pm 3.6$ & $18.4 \pm 3.6$ & $18.7 \pm 3.8$ & $18.6 \pm 3.8$ & $18.5 \pm 3.7$ & $18.4 \pm 3.7$ \\
\hline Baseline SOFAS (mean \pm SD) & $62.1 \pm 9.4$ & $62.3 \pm 9.1$ & $62.3 \pm 9.0$ & $61.7 \pm 9.4$ & $61.4 \pm 9.1$ & $61.1 \pm 8.8$ & $60.9 \pm 9.0$ & $61.0 \pm 8.6$ \\
\hline
\end{tabular}

SOFAS, Social and Occupational Functioning Assessment Scale.

restricted to this early point in clinical care. The emergence of circadian, manic, or psychotic phenomena may occur at various points across the course of illness; therefore, a greater proportion of individuals in the circadian-bipolar spectrum and neurodevelopmentalpsychosis subgroups would be expected at later time points. Accordingly, initial longitudinal data indicate that around $13 \%$ of those in the Optymise cohort transition across these pathophysiological mechanism pathways during the course of care, with an additional $14 \%$ transitioning to later clinical stages within the same pathway. ${ }^{42}$ Clinical staging and pathophysiological mechanisms are independent but complementary classification systems, with clinical stage reflecting the severity and persistence of illness, and proposed pathophysiological mechanisms reflecting the type of illness.

Deliberate self-harm and suicidal thoughts and behaviour were common at baseline, with rates concordant with previous studies in mentally ill samples ${ }^{75} 76$ and much higher than the general adolescent population. ${ }^{77} 78$ The presence of such high rates of deliberate self-harm and suicidal thoughts and behaviour early in the course of care highlights the specific need for risk reduction strategies and ongoing management of these thoughts and behaviours during care and treatment. A report on suicide attempts in this cohort ${ }^{79}$ found that the presence of a prior suicide attempt at baseline increases not only the risk for subsequent deliberate self-harm and suicidal thoughts and behaviours but also other negative outcomes including onset of alcohol or substance use disorder and bipolar disorder. This demonstrates the utility of this dataset in assessing prospective risk for multiple outcome domains in relation to baseline features.

\section{STRENGTHS AND LIMITATIONS}

The Optymise cohort will provide an important resource to evaluate outcomes and understand the course of mental illness in young people presenting for mental health care and treatment. The large transdiagnostic sample, and selection based on presentation for care rather than specific diagnostic, severity, or risk-related criteria, allows for appropriate variance along dimensions of interest and provides a sample representative of those presenting to clinical services. This approach maximises the potential for clinically meaningful conclusions to be drawn. The assessment of multidimensional outcomes affords an important level of detail. It will allow examination of inter-relationships between these domains and inform appropriate confounding factors to be considered in subsequent analyses. Longitudinal assessment, using all available data will be another strength of this study, with standardised follow-up time points as well as a 'time last seen' time point capturing information across the full duration of time in care. The linkage of this longitudinal data with more in-depth assessments from related neuropsychological and neurobiological studies will further strengthen the richness of this dataset and increase the potential for greater understanding of the underpinnings of the development of mental illness in young people.

There are important limitations of this study. Due to the method of data collection (ie, data extraction from clinical and research files), there is considerable variability in the quantity and quality of clinical information available. This has an adverse impact on the consistency of the measures. It is important to note that this will likely result in some under-reporting or conservative estimates of the incidence of certain parameters, as the absence of clinical information may mean the information is unavailable or missing, not assessed by the clinician, or simply not clinically relevant. However, the data most consistently available in clinical files likely reflect the measures that are most widely used by treatment providers in an everyday context. This will increase the generalisability of the findings and take advantage of existing approaches to clinical assessment. It is also important to note that those with available follow-up time points are drawn from those continuing to engage with clinical care over a longer period. This may introduce some bias in the follow-up sample towards those individuals with more severe, persistent, or recurrent illness.

\section{CONCLUSION}

This paper reports on the methods, baseline characteristics, follow-up rates, and initial findings of the $\mathrm{BMC}$ Optymise cohort, an observational study tracking a range of demographic, clinical, functional, and comorbid risk outcomes longitudinally in young individuals presenting for mental health care and treatment. The cohort is broadly representative of young people presenting to mental health care services in terms of demographic and clinical features. Initial publications from the cohort indicate a number of factors are associated with transition to 
later clinical stages, long-term social and occupational function typically remains poor, and that prior suicide attempts at baseline are predictive of a range of negative outcomes. Further work in this cohort will follow the longitudinal course of mental illness and associated multidimensional outcome domains in young people presenting for mental health care and treatment, and will allow for testing of the relative predictive validity of various illness characteristics and outcome domains. Future plans include exploring the bidirectional longitudinal relationships between functional recovery and other adverse outcomes, characterising longitudinal transitions across clinical stages and pathophysiological mechanisms to provide greater insight into the emergence and development of specific syndromes across the course of care, and analysing the predictive value of at-risk mental states in relation to multidimensional outcomes. Characterising the longitudinal relationships between the clinical, functional, and other associated risk factors in this population (including associated neurobiological factors) and investigating their predictive value across multiple outcomes domains is important for the development of prevention and intervention strategies to improve mental health care and address the broad range of outcomes contributing to the burden of disease.

\section{COLLABORATION}

The BMC welcomes collaboration involving the Optymise cohort, subject to appropriate ethical approval, permissions and research agreements. This may include collaboration on analysis of the currently available data, as well as collaboration on collection of new data at follow-up time points and further substudies with measures in a specific domain. Interested parties should contact ian.hickie@ sydney.edu.au with details of the proposed collaboration.

\section{Author affiliations}

${ }^{1}$ Brain \& Mind Centre, The University of Sydney, Camperdown, New South Wales, Australia

${ }^{2}$ School of Psychology, The University of Sydney, Camperdown, New South Wales, Australia

${ }^{3}$ Department of Psychology, Macquarie University, Sydney, New South Wales,

Australia

${ }^{4}$ Charles Perkins Centre, The University of Sydney, Camperdown, New South Wales, Australia

${ }^{5}$ Thompson Institute, University of the Sunshine Coast, Birtinya, Queensland, Australia

${ }^{6}$ Department of Academic Psychiatry, Newcastle University, Newcastle, United Kingdom

${ }^{7}$ Diderot University, Sorbonne City, Paris, France

${ }^{8}$ School of Medicine, University of Notre Dame, Sydney, New South Wales, Australia

Acknowledgements We would like to thank all the young people who have participated in this study, and all the staff in the Youth Mental Health Team at the Brain and Mind Centre, past and present, who have contributed to this work.

Contributors IBH, DFH, JC, EMS, SLN, AJG, Fl, and JSC were involved in study conception, design and planning, and are involved in ongoing planning, analysis, and publication of the data from this cohort. SC, JJC, JRP, and AEW are also involved in ongoing planning, analysis, and publication of the data from this cohort. AN, NZ, JJC, and DW are involved in study coordination and data collection. JSC drafted the manuscript. All authors contributed to and have approved the final manuscript.

Funding This work was partially supported by grants from the National Health \& Medical Research Council including: Centre of Research Excellence (№. 1061043), Australia Fellowship (No. 511921 awarded to Prof Hickie), and Clinical Research Fellowship (No. 402864 awarded to Prof Naismith). Dr Carpenter was supported by the Caroline Quinn Research Grant.

Competing interests Professor Sharon Naismith has received honoraria for an educational seminar for Lundbeck. A/Professor Elizabeth Scott is the Medical Director, Young Adult Mental Health Unit, St Vincent's Hospital Darlinghurst, Discipline Leader of Adult Mental Health, School of Medicine, University of Notre Dame, Research Affiliate, The University of Sydney and Consultant Psychiatrist. She has received honoraria for educational seminars related to the clinical management of depressive disorders supported by Servier and Eli-Lilly pharmaceuticals. She has participated in a national advisory board for the antidepressant compound Pristiq, manufactured by Pfizer. She was the National Coordinator of an antidepressant trial sponsored by Servier. Professor lan Hickie has been a Commissioner in Australia's National Mental Health Commission since 2012. He is the Co-Director, Health and Policy at the Brain and Mind Centre (BMC) University of Sydney. The BMC operates an early-intervention youth services at Camperdown under contract to headspace. Professor Hickie has previously led community-based and pharmaceutical industrysupported (Wyeth, Eli Lily, Servier, Pfizer, AstraZeneca) projects focused on the identification and better management of anxiety and depression. He is a Board Member of Psychosis Australia Trust and a member of Veterans Mental Health Clinical Reference group. He is the Chief Scientific Advisor to, and an equity shareholder in, InnoWell. InnoWell has been formed by the University of Sydney and PwC to administer the \$30M Australian Government Funded Project Synergy. Project Synergy is a 3-year programme for the transformation of mental health services through the use of innovative technologies.

Patient and public involvement Patients and/or the public were involved in the design, or conduct, or reporting or dissemination plans of this research. Refer to the Methods section for further details.

Patient consent for publication Not required.

Ethics approval The study was approved by the University of Sydney Human Research Ethics Committee (project numbers 2008/5453 and 2012/1626).

Provenance and peer review Not commissioned; externally peer reviewed.

Data availability statement Deidentified data from the database can be made available from the corresponding author on reasonable request.

Open access This is an open access article distributed in accordance with the Creative Commons Attribution Non Commercial (CC BY-NC 4.0) license, which permits others to distribute, remix, adapt, build upon this work non-commercially, and license their derivative works on different terms, provided the original work is properly cited, appropriate credit is given, any changes made indicated, and the use is non-commercial. See: http://creativecommons.org/licenses/by-nc/4.0/.

\section{ORCID iDs}

Joanne S Carpenter http://orcid.org/0000-0002-9766-6700

Frank lorfino http://orcid.org/0000-0003-1109-0972

Shane Cross http://orcid.org/0000-0002-5413-8342

Natalia Zmicerevska http://orcid.org/0000-0001-7649-4711

Jacob J Crouse http://orcid.org/0000-0002-3805-2936

Jake R Palmer http://orcid.org/0000-0001-8253-0483

Daniel F Hermens http://orcid.org/0000-0002-8570-2663

Jan Scott http://orcid.org/0000-0002-7203-8601

Elizabeth M Scott http://orcid.org/0000-0003-3907-0324

lan B Hickie http://orcid.org/0000-0001-8832-9895

\section{REFERENCES}

1 Gustavsson A, Svensson M, Jacobi F, et al. Cost of disorders of the brain in Europe 2010. Eur Neuropsychopharmacol 2011;21:718-79.

2 Gore FM, Bloem PJN, Patton GC, et al. Global burden of disease in young people aged 10-24 years: a systematic analysis. Lancet 2011;377:2093-102.

3 Lopez AD, Mathers CD, Ezzati M, et al. Global and regional burden of disease and risk factors, 2001: systematic analysis of population health data. Lancet 2006;367:1747-57.

4 Erskine HE, Moffitt TE, Copeland WE, et al. A heavy burden on young minds: the global burden of mental and substance use disorders in children and youth. Psychol Med 2015;45:1551-63. 
5 McGorry PD, Goldstone SD, Parker AG, et al. Cultures for mental health care of young people: an Australian blueprint for reform. Lancet Psychiatry 2014;1:559-68.

6 Hickie IB, Scott EM, Hermens DF, et al. Applying clinical staging to young people who present for mental health care. Early Interv Psychiatry 2013;7:31-43.

7 Scott EM, Hermens DF, Glozier N, et al. Targeted primary carebased mental health services for young Australians. Med J Aust 2012;196:136-40.

8 Insel TR. Translating scientific opportunity into public health impact: a strategic plan for research on mental illness. Arch Gen Psychiatry 2009;66:128-33.

9 Insel TR. The arrival of preemptive psychiatry. Early Interv Psychiatry 2007;1:5-6.

10 Jones PB. Adult mental health disorders and their age at onset. $\mathrm{Br} \mathrm{J}$ Psychiatry 2013;202:s5-10.

11 Fergusson DM, Horwood LJ, Ridder EM, et al. Subthreshold depression in adolescence and mental health outcomes in adulthood. Arch Gen Psychiatry 2005;62:66-72.

12 Axelson DA, Birmaher B, Strober MA, et al. Course of subthreshold bipolar disorder in youth: diagnostic progression from bipolar disorder not otherwise specified. J Am Acad Child Adolesc Psychiatry 2011;50:1001-16.

13 Sullivan PF, Daly MJ, O'Donovan M. Genetic architectures of psychiatric disorders: the emerging picture and its implications. Nat Rev Genet 2012;13:537-51.

14 Buckholtz JW, Meyer-Lindenberg A. Psychopathology and the human connectome: toward a transdiagnostic model of risk for mental illness. Neuron 2012;74:990-1004.

15 Waszczuk MA, Zavos HMS, Gregory AM, et al. The phenotypic and genetic structure of depression and anxiety disorder symptoms in childhood, adolescence, and young adulthood. JAMA Psychiatry 2014;71:905-16.

16 Kendler KS, Aggen SH, Knudsen GP, et al. The structure of genetic and environmental risk factors for syndromal and subsyndromal common DSM-IV axis I and all axis II disorders. Am J Psychiatry 2011:168:29-39.

17 Pettersson E, Larsson H, Lichtenstein P. Common psychiatric disorders share the same genetic origin: a multivariate sibling study of the Swedish population. Mol Psychiatry 2016;21:717-21.

18 Eaton NR, Rodriguez-Seijas C, Carragher N, et al. Transdiagnostic factors of psychopathology and substance use disorders: a review. Soc Psychiatry Psychiatr Epidemiol 2015;50:171-82.

19 Rickwood D, Paraskakis M, Quin D, et al. Australia's innovation in youth mental health care: the headspace centre model. Early Interv Psychiatry 2019;13:159-66.

20 McGorry PD, Tanti C, Stokes R, et al. headspace: Australia's National Youth Mental Health Foundation--where young minds come first. Med J Aust 2007;187:S68-70.

21 McGorry P, Bates T, Birchwood M. Designing youth mental health services for the 21st century: examples from Australia, Ireland and the UK. Br J Psychiatry Supp/ 2013;54:s30-5.

22 Iorfino F, Hickie IB, Lee RSC, et al. The underlying neurobiology of key functional domains in young people with mood and anxiety disorders: a systematic review. BMC Psychiatry 2016;16:156.

23 Scott EM, Carpenter JS, lorfino F, et al. Early intervention, prevention, and prediction in mood disorders: Tracking multidimensional outcomes in young people presenting for mental health care. In: Baune BT, ed. Personalized psychiatry. Academic Press, 2020: 39-62

24 Iorfino F, Carpenter JS, Cross SP, et al. Multidimensional outcomes in youth mental health care: what matters and why? Med J Aust 2019;211:S4-11.

25 Gibb SJ, Fergusson DM, Horwood LJ. Burden of psychiatric disorder in young adulthood and life outcomes at age 30 . Br J Psychiatry 2010;197:122-7.

26 Copeland WE, Wolke D, Shanahan L, et al. Adult functional outcomes of common childhood psychiatric problems: a prospective, longitudinal study. JAMA Psychiatry 2015;72:892-9.

27 Buist-Bouwman MA, De Graaf R, Vollebergh WAM, et al. Functional disability of mental disorders and comparison with physical disorders: a study among the general population of six European countries. Acta Psychiatr Scand 2006;113:492-500.

28 Donohue JM, Pincus HA. Reducing the societal burden of depression. Pharmacoeconomics 2007;25:7-24.

29 Cuthbert BN, Insel TR. Toward the future of psychiatric diagnosis: the seven pillars of RDoC. BMC Med 2013:11:126.

30 Kozak MJ, Cuthbert BN. The NIMH research domain criteria initiative: background, issues, and pragmatics. Psychophysiology 2016;53:286-97.
31 Insel T, Cuthbert B, Garvey M, et al. Research domain criteria (RDoC): toward a new classification framework for research on mental disorders. Am J Psychiatry 2010;167:748-51.

32 Casey BJ, Craddock N, Cuthbert BN, et al. DSM-5 and RDoC: progress in psychiatry research? Nat Rev Neurosci 2013;14:810-4

33 Goldman HH, Skodol AE, Lave TR. Revising axis V for DSMIV: a review of measures of social functioning. Am J Psychiatry 1992;149:1148-56.

34 Hilsenroth MJ, Ackerman SJ, Blagys MD, et al. Reliability and validity of DSM-IV axis V. Am J Psychiatry 2000;157:1858-63.

35 Hay P, Katsikitis M, Begg J, et al. A two-year follow-up study and prospective evaluation of the DSM-IV axis V. Psychiatr Serv 2003;54:1028-30.

36 Rickwood DJ, Mazzer KR, Telford NR, et al. Changes in psychological distress and psychosocial functioning in young people visiting headspace centres for mental health problems. Med $\mathrm{J}$ Aust 2015;202:537-42.

37 American Psychiatric Association. Diagnostic and statistical manual of mental disorders. 5th edn. Arlington, VA: American Psychiatric Pub, 2013.

38 McGorry PD, Hickie IB, Yung AR, et al. Clinical staging of psychiatric disorders: a heuristic framework for choosing earlier, safer and more effective interventions. Aust N Z J Psychiatry 2006;40:616-22.

39 McGorry PD, Purcell R, Hickie IB, et al. Clinical staging: a heuristic model for psychiatry and youth mental health. Med J Aust 2007;187:S40-2.

40 Hickie IB, Hermens DF, Naismith SL, et al. Evaluating differential developmental trajectories to adolescent-onset mood and psychotic disorders. BMC Psychiatry 2013;13:303.

41 Hickie IB, Naismith SL, Robillard R, et al. Manipulating the sleepwake cycle and circadian rhythms to improve clinical management of major depression. BMC Med 2013;11:79.

42 Carpenter JS, lorfino F, Cross SP, et al. Combining clinical stage and pathophysiological mechanisms to understand illness trajectories in young people with emerging mood and psychotic syndromes. Med $J$ Aust 2019;211:S12-22.

43 Kelleher I, Keeley H, Corcoran P, et al. Clinicopathological significance of psychotic experiences in non-psychotic young people: evidence from four population-based studies. Br J Psychiatry 2012;201:26-32.

44 Kelleher I, Cannon M. Psychotic-like experiences in the general population: characterizing a high-risk group for psychosis. Psychol Med 2011:41:1-6.

45 Hauser M, Correll CU. The significance of at-risk or prodromal symptoms for bipolar I disorder in children and adolescents. Can J Psychiatry 2013;58:22-31.

46 Faedda GL, Marangoni C, Serra G, et al. Precursors of bipolar disorders: a systematic literature review of prospective studies. J Clin Psychiatry 2015;76:614-24.

47 Alvaro PK, Roberts RM, Harris JK. A systematic review assessing bidirectionality between sleep disturbances, anxiety, and depression. Sleep 2013;36:1059-68.

48 Addington AM, Gallo JJ, Ford DE, et al. Epidemiology of unexplained fatigue and major depression in the community: the Baltimore ECA follow-up, 1981-1994. Psychol Med 2001;31:1037-44.

49 Hallgren KA. Computing inter-rater reliability for observationa data: an overview and tutorial. Tutor Quant Methods Psychol 2012;8:23-34.

50 Australian Institute of Health and Welfare. Young Australians: their health and wellbeing. Canberra: AlHW, 2011.

51 Rickwood DJ, Telford NR, Parker AG, et al. headspace - Australia's innovation in youth mental health: who are the clients and why are they presenting? Med J Aust 2014;200:108-11.

52 Scott J, Scott EM, Hermens DF, et al. Functional impairment in adolescents and young adults with emerging mood disorders. $\mathrm{Br} \mathrm{J}$ Psychiatry 2014;205:362-8.

53 Jansen K, Magalhães PVS, Tavares Pinheiro R, et al. Early functional impairment in bipolar youth: a nested population-based case-contro study. J Affect Disord 2012;142:208-12.

54 Roberts RE, Fisher PW, Turner JB, et al. Estimating the burden of psychiatric disorders in adolescence: the impact of subthreshold disorders. Soc Psychiatry Psychiatr Epidemiol 2015;50:397-406.

55 Holloway EM, Rickwood D, Rehm IC, et al. Non-participation in education, employment, and training among young people accessing youth mental health services: demographic and clinical correlates. Advances in Mental Health 2018;16:19-32.

56 OECD. Youth not in employment, education or training (NEET) (indicator), 2018 [Accessed 17 Aug 2018]

57 lorfino F, Hermens DF, Cross SP, et al. Delineating the trajectories of social and occupational functioning of young people attending early 
intervention mental health services in Australia: a longitudinal study. BMJ Open 2018;8:e020678.

58 Lee RSC, Hermens DF, Scott J, et al. A transdiagnostic study of education, employment, and training outcomes in young people with mental illness. Psychol Med 2017;47:2061-70.

59 Fergusson DM, Horwood LJ, Lynskey MT. The effects of unemployment on psychiatric illness during young adulthood. Psychol Med 1997;27:371-81.

60 Luciano A, Bond GR, Drake RE. Does employment alter the course and outcome of schizophrenia and other severe mental illnesses? A systematic review of longitudinal research. Schizophr Res 2014;159:312-21.

61 Merikangas KR, He J-P, Burstein M, et al. Lifetime prevalence of mental disorders in U.S. adolescents: results from the National Comorbidity Survey Replication--Adolescent Supplement (NCS-A). J Am Acad Child Adolesc Psychiatry 2010;49:980-9.

62 Slade T, Johnston A, Oakley Browne MA, et al. 2007 national survey of mental health and wellbeing: methods and key findings. Aust N Z J Psychiatry 2009;43:594-605.

63 Merikangas KR, He J-ping, Burstein M, et al. Service utilization for lifetime mental disorders in U.S. adolescents: results of the National comorbidity Survey-Adolescent supplement (NCS-A). J Am Acad Child Adolesc Psychiatry 2011:50:32-45.

64 Hamilton BA, Naismith SL, Scott EM, et al. Disability is already pronounced in young people with early stages of affective disorders: data from an early intervention service. J Affect Disord 2011;131:84-91.

65 Burgess PM, Pirkis JE, Slade TN, et al. Service use for mental health problems: findings from the 2007 national survey of mental health and wellbeing. Aust N Z J Psychiatry 2009;43:615-23.

66 Purcell R, Jorm AF, Hickie IB, et al. Demographic and clinical characteristics of young people seeking help at youth mental health services: baseline findings of the transitions study. Early Interv Psychiatry 2015;9:487-97.

67 Kelleher I, Connor D, Clarke MC, et al. Prevalence of psychotic symptoms in childhood and adolescence: a systematic review and meta-analysis of population-based studies. Psychol Med 2012;42:1857-63.
68 McGrath JJ, Saha S, Al-Hamzawi A, et al. Psychotic experiences in the general population: a cross-national analysis based on 31,261 Respondents from 18 countries. JAMA Psychiatry 2015;72:697-705.

69 Scott J, Chant D, Andrews G, et al. Psychotic-like experiences in the general community: the correlates of CIDI psychosis screen items in an Australian sample. Psychol Med 2006;36:231-8.

70 Hodgekins J, Lower R, Wilson J, et al. Clinician-rated and selfreported psychotic-like experiences in individuals accessing a specialist youth mental health service. Br J Clin Psychol 2018:57:367-81.

71 Kelleher I, Devlin N, Wigman JTW, et al. Psychotic experiences in a mental health clinic sample: implications for suicidality, multimorbidity and functioning. Psychol Med 2014;44:1615-24.

72 Cross SPM, Hermens DF, Hickie IB. Treatment patterns and shortterm outcomes in an early intervention youth mental health service. Early Interv Psychiatry 2016;10:88-97.

73 Iorfino F, Scott EM, Carpenter JS, et al. Clinical stage transitions in persons aged 12 to 25 years presenting to early intervention mental health services with anxiety, mood, and psychotic disorders. JAMA Psychiatry 2019. doi:10.1001/jamapsychiatry.2019.2360. [Epub ahead of print: 28 Aug 2019].

74 Scott EM, Hermens DF, White D, et al. Body mass, cardiovascular risk and metabolic characteristics of young persons presenting for mental healthcare in Sydney, Australia. BMJ Open 2015;5:e007066.

75 Chen YW, Dilsaver SC. Lifetime rates of suicide attempts among subjects with bipolar and unipolar disorders relative to subjects with other axis I disorders. Biol Psychiatry 1996;39:896-9.

76 Scott EM, Hermens DF, Naismith SL, et al. Thoughts of death or suicidal ideation are common in young people aged 12 to 30 years presenting for mental health care. BMC Psychiatry 2012;12.

77 Hawton K, Saunders KEA, O'Connor RC. Self-harm and suicide in adolescents. Lancet 2012;379:2373-82.

78 Muehlenkamp JJ, Claes L, Havertape L, et al. International prevalence of adolescent non-suicidal self-injury and deliberate selfharm. Child Adolesc Psychiatry Ment Health 2012;6:10.

79 lorfino F, Hermens DF, Cross SPM, et al. Prior suicide attempts predict worse clinical and functional outcomes in young people attending a mental health service. J Affect Disord 2018;238:563-9. 